Editorial

\title{
Innovation in the European Energy Sector and Regulatory Responses to It: Guest Editorial Note
}

\author{
Thomas Hoppe $^{1, *(\mathbb{D})}$, Anna Butenko ${ }^{2}$ and Michiel Heldeweg ${ }^{3}$ \\ 1 Organisation and Governance (OG), Department of Multi-Actor Systems (MAS), Faculty of Technology, \\ Policy and Management (TPM), Delft University of Technology, Jaffalaan 5, 2628 BX Delft, The Netherlands \\ 2 Tilburg Law and Economics Center (TILEC), Tilburg University, Professor Cobbenhagenlaan 221, \\ Montesquieu Building, 5037 DE Tilburg, The Netherlands; a.s.butenko@uva.nl \\ 3 Department of Technology and Governance for Sustainability (CSTM), Institute for Innovation and \\ Governance Studies (IGS), Faculty of Behavioral, Management and Social Studies (BMS), \\ University of Twente, 7500 AE Enschede, The Netherlands; m.a.heldeweg@utwente.nl \\ * Correspondence: T.Hoppe@tudelft.nl; Tel.: +31-15-278-2783
}

Received: 2 February 2018; Accepted: 4 February 2018; Published: 6 February 2018

\begin{abstract}
The European energy sector is an important economic sector that is also traditionally highly regulated. With the increasing tempo in which innovations in technology and markets occur, catalysed inter alia by the energy transition and accompanied by new formats of innovation (disruptive and bottom-up), the question arises whether existing regulatory frameworks sufficiently allow for such innovation and support its further development. From an editorial perspective, we argue that decentralization of energy production on the national level and that of regulatory responses to it, need more scholarly attention. In this guest editorial, the contributions of nine articles to our special issue on innovation in the European energy sector and regulatory responses to it, are addressed. First, lessons on regulatory response to innovations in European energy markets are drawn. Second, several types of responses are deduced and discussed. Finally, key observations and suggestions for further research are presented.
\end{abstract}

Keywords: innovation; European Union; regulatory response; energy governance; energy policy; energy transition; renewable energy; community energy; multi-level governance; experimentation

\section{Introduction}

The European energy sector is an important sector that is also highly regulated. Innovation in this sector used to be characterized as mostly incremental and top-down, while introduction of most renewable energy technologies underwent troublesome trajectories [1]. With the increasing tempo in which innovations in technology and markets occur, catalysed inter alia by the energy transition and accompanied by new formats of innovation (disruptive and bottom-up), the question arises whether existing regulatory frameworks sufficiently allow for such innovation and support its further development.

The traditional European energy system, in terms of its technical and commercial, market design, as well as the regulatory framework supporting it, is still organized according to the equally traditional value chain of energy production, transport, storage and distribution. However, the current European energy market is far from static. In recent years many developments have changed its structure. First, liberalization and the EU drive to establish an integrated internal market pushed the dynamics of the energy market towards a pan-European, harmonized and coordinated model [2]. Second, against the backdrop of technological innovation, intensifying security of supply and climate change concerns triggered the emergence of renewable energy sources (RES) in the energy mix of the Member States [3]. RES are usually produced in a more decentralized manner compared to traditional fossil energy 
sources. Combined with an increased level of energy-related awareness of the population, as well as technological progress and respective increasing affordability of technology, this created a bottom-up pull in the energy market towards distributed and smaller-scale energy production [3].

Thereby, the current European energy market is experiencing several conflicting forces. First, on the vertical axis, there is a multi-level governance issue, particularly a push towards more centralization on the European level and at the same time a pull towards more decentralization on the national level. Second, on the horizontal axis, there is a multi-actor governance issue, such as the governance of decentralized RES production by citizens, as well as market and government actors.

Whereas the central pull towards European harmonization has received a lot of academic attention [4], innovative decentralization of energy production on the national level and that of regulatory responses to it, has received relatively less. This special issue aims to contribute to filling this academic gap, especially from a law and policy perspective. Moreover, in this special issue we aim to focus on both the 'traditional' regulatory responses to innovation taking place in the energy sector and on the more recent regulatory reactions to current innovations, such as grassroots initiatives for renewable energy. From an editorial perspective, the contributors to our special issue managed to achieve this goal. It is now our task to map out the common themes emerging from the contributions, as well as to identify the topics where further research is necessary.

This special issue mostly comprises papers that were presented at a panel session during the European Consortium for Political Research' (ECPR), 6th Standing Group on Regulatory Governance Biennial Conference (6-8 July 2016, Tilburg University, Tilburg, The Netherlands). The special issue was organized and funded by the research colloquium on 'Energy and Climate Governance' of the Netherlands Institute of Government studies (NIG), a research network that was founded in 2013 and has since been active in organizing academic venues and streamlining multi-disciplinary research relevant to the issues of governance of energy transition and climate change mitigation. Previous special issues edited by members of the research colloquium concerned 'Governance of climate mitigation and energy issues' [4]. 'Governing the climate challenge and energy transition in cities' [5] and 'Energy transition and local governance' [6].

This guest editorial note is divided in three main parts: The first part focuses on the innovation concept in general and on the innovation currently taking shape in the European energy market. The second part discusses the possible regulatory approaches to innovation according to the contributors to this special issue. The third part analyses the lessons learned and sets out an agenda for further research.

\section{Innovation in the European Energy Market}

\subsection{General Discussion}

Prior to jumping head-first into the discussion on regulatory responses to innovation in the energy sector, it is important to discuss what we mean by the term 'innovation.' The focus of the current special issue is upon innovations in the energy sector, that are considered positive and socially and environmentally desirable.

Innovation is a complex phenomenon that is studied from multiple disciplinary angles and even has a dedicated academic research stream-innovation studies. The academic literature in this field traditionally distinguishes between product and process innovation [7]. Innovation is often assumed to be technological in nature. However, this does not necessarily to all innovations, since there are also market and social innovations, which rely on new ideas and approaches applied to economic and social challenges [8]. The same can be said about institutional and policy innovations [9], often in response to grand societal challenges and environmental change.

In recent decades, significant progress has been made in furthering academic thinking about innovation. Besides the traditional categories of radical versus incremental innovation [10], in the 1990s Christensen enriched both academic and business discourse with the categories of disruptive 
versus sustaining innovation [11]. Sustaining innovation is developed by a market party within the so-called established value network, referring to the existing set of clients and shareholders. Sustaining innovation could be either radical or incremental- the two dichotomies are not mutually exclusive. In contrast, disruptive innovation is usually underperforming for the clients within the value network of the market party and hence does not initially represent an attractive option for investment and development. However, as the emerging disruptive innovation grows and matures, its performance improves and it gradually captures a part of the incumbent's value network and thus its profits. Thus, when faced with a competing disruptive innovation, market players could lose their dominant position on the market simply by doing what they are doing best-serving and listening to their clients. Indeed, according to Christensen, established market actors are typically better at sustaining innovation and often fail at disruptive ones, whereas new entrants tend to dominate in the latter. Herein lies the key to the fascination of both academic and business audience with this simple concept and its subsequent popularity.

The concept of disruptive innovation is further elaborated by Gans [12], who 'identifies two kinds of disruption: demand-side, when successful firms focus on their main customers and underestimate market entrants with innovations that target niche demands; and supply-side, when firms focused on developing existing competencies become incapable of developing new ones' [13]. While demand-side disruption aligns with the concept interpretation by Christensen, the supply-side disruption as proposed by Gans builds upon the definition of architectural innovation by Henderson and Clark [14]. More specifically, these authors distinguish between component or modular innovation, referring to innovation in the individual elements and architectural innovation, referring to 'the reconfiguration of an established system to link together existing components in a new way' [14]. In other words, Henderson and Clark make a clear 'distinction between the product as a system and the product as a set of components' [14]. According to Gans, disruptive supply-side (architectural) innovation is more challenging for a market party to handle compared to disruptive demand-side innovation, because it requires changes both in the business model of a market party and its internal organization [12].

The understanding of innovation was further enriched by Chesbrough, who proposed the concept of open versus closed innovation [15]. In making this distinction, he emphasized the different paths which an invention could take to the market. In a closed innovation environment, the market party researches and develops the product or service 'in house,' as well as uses its own channels to bring it to market. In contrast, in an open innovation environment, the party in question simply buys the inventions and markets them via various channels, some of which could be outsourced. As the author puts it, 'open innovation can be understood as the antithesis of the traditional vertical integration approach where internal R\&D activities lead to internally developed products that are then distributed by the firm' [16]. It is, however, important to note that the concept of open innovation does not presume that the innovation is free of intellectual property rights.

While Chesbrough focuses on the path to the market, Von Hippel emphasizes the actors who innovate: [17] He distinguishes between manufacturer-centric and user-centric (or democratic) innovation. These innovation types are also referred to, respectively, as top-down and bottom-up innovation [17]. Whereas manufacturer-based innovation originates with producers of products and services who bring them to the market, user-centred innovation is realized by the consumers themselves. In contrast to Chesbrough's open innovation, Von Hippel's user-centric innovation often does rely on sharing information openly. Indeed, users as 'innovators often freely reveal (their innovation) because it is often the best or the only practical option available to them' [17].

Now that the common typology of innovation has been clarified, our attention turns to the innovation that is currently taking place in the European energy market. This is discussed in the following section. 


\subsection{Innovation in European Energy Market}

In the 20th century the European energy market landscape used to be dominated by a few large vertically integrated undertakings (VIUs) maintaining significant market power. The VIUs often had in-house research and development departments and thus adopted the closed innovation paradigm. Moreover, innovation typically occurred within the existing value network of the VIUs and thus was sustaining. The pace and frequency of changes in the sector were not high and it was characterized by incremental component innovation. This innovation was also mostly manufacturerand supplier-centric.

The beginning of this century was marked by the process of liberalization and EU energy market opening to competition. The VIUs were unbundled-production and supply were separated from transmission and distribution infrastructure, with each task going to a separate company. The dominant view in the law and economics academic literature is that competition is more conducive to innovation compared to monopoly [18]. As the companies must compete for a market share, they have an incentive to introduce new products and services ('product innovation'), as well as become more efficient and reduce their production costs ('process innovation') [7]. The changes to the pace and intensity of innovation in the European energy market after liberalization certainly confirm this hypothesis. Moreover, the type of innovation characterizing the sector changed. These changes could be understood along two main dimensions-that of disruptive demand-side (component) innovation and that of disruptive supply-side (architectural) innovation. The contributions to this special issue provide several illustrative examples of innovation currently taking shape in the European energy sector. These examples are discussed below along the two proposed dimensions.

\subsubsection{Disruptive (Demand-Side) Component Innovation}

The transition of the energy sector towards integration of RES (also referred to as 'energy transition') is catalysed by the urgent need to minimize carbon emissions, by the security of supply concerns as global fossil energy supplies start to decline, as well as by shifts in societal preferences and increased (environmental) awareness. Of course, energy transition would not be possible if it were not for technical innovations that allowed to capture the energy of the renewable sources, such as wind and sun. The innovative means of energy production, such as wind turbines, solar panels, or heat pumps, were brought to the market by the new entrants. These RES production technologies were initially much more expensive and less efficient compared to the traditional fossil fuels and thus did not appeal to the incumbents. They could only serve a limited number of fringe customers, who valued other characteristics of energy, such as the sustainability aspect, or independence of large energy suppliers. As such, RES production technologies represented both radical and disruptive component innovation taking place in the European energy market.

Besides technical innovation in relation to RES production, market and social innovation were also taking shape. In his article, Hufen discusses the market for the so-called green (renewable) electricity in Europe, by using the example of the Netherlands. According to the author, Dutch consumers are 'excited by the idea of buying green energy and contributing to the mitigation of negative climate effects' [19]. Thus, for such consumers grey (fossil-based) electricity is not a substitute for green electricity, even though the two are physically indistinguishable in terms of quality. In such conditions, a certification system was necessary to administratively label green electricity and to allow consumers to exercise their right to choose a supplier based on their preferences in relation to a product (e.g., cheap versus expensive, green versus grey, good service versus bad service). As the result, the so-called Guarantees of Origin were introduced by the European Commission. A 'guarantee of origin' (GO) refers to 'an electronic document which has the sole function of providing proof to a final customer that a given share or quantity of energy was produced from renewable sources' [20]. GOs represent a product innovation that is not technical but rather market in nature. Indeed, it could be argued that green electricity does not differ from grey electricity in its physical product characteristics but it has a different target audience and requires new ways of marketing. 


\subsubsection{Disruptive (Supply-Side) Architectural Innovation}

As the innovative energy production means, such as wind turbines and solar panels, penetrated the market, they caused architectural shifts in the European energy market landscape. These shifts took place both in relation to infrastructure (system operation) and to the roles and responsibilities of different actors in the market (market organization) [21].

Scholten and Künneke describe energy infrastructures as 'complex, adaptive socio-technical systems' [21]. Such definition is consistent with the definition of architectural innovation as system innovation. Moreover, the authors define the traditional energy market value chain as 'upstream (exploration, production and trade), midstream (transportation, refinement and storage) and downstream (distribution, metering, retail and consumption)' [21].

Wind turbines, solar panels, heat pumps and other innovative technologic solutions enabled RES production in a decentralized manner, which had a significant impact on the value chain of the European energy market. More specifically, this meant that energy was not any longer flowing in one direction from a producer to a supplier and then to a consumer but could also be produced by the consumer herself. The commodity flow in the traditional value chain became bi-directional. Moreover, consumers were no longer restricted to a passive customer role but could produce their own energy and trade it on the market. Thus, not only the commodity flow but also the monetary one, were disrupted. European energy consumers were also increasingly engaging in innovation themselves and not depending on the suppliers to do so for them. These changes resulted in the disruptive architectural innovation in the European energy market, both supplier- and user-centric. Several contributions to this special issue discuss examples of such (supply-side) architectural innovation occurring in the European energy market.

The article by Oteman, Kooij and Wiering focuses on the emergence of grassroots initiatives in the Netherlands. Grassroots initiatives (GIs) for renewable energy are defined as 'local, bottom-up collaborations between citizens, motivated by the desire to supply or produce renewable energy on local scale' [22]. The article traces several waves of the GIs in the Netherlands. The first wave of pioneering initiatives emerged largely in protest to nuclear energy in mid-1980s and had the format of the citizens' cooperatives owning and operating wind turbines [22]. The second wave of wind cooperatives took shape in early 1990s in the Dutch Northern province of Friesland. The motivation behind these initiatives was different than that of the previous wave. The authors argue that these wind turbines were built 'not out of environmental concerns but also with the purpose of generating profits for the local community' [22]. The early 2000s witnessed the third wave of GIs take off-these initiatives were much more diverse in their format (wind, solar), size and focus compared to their predecessors. Indeed, new initiatives had the ambition to engage in a much broader range of activities, such as 'collective purchase of privately owned solar panels and providing members with information about energy savings and production' [22]. The latest wave of GIs (2009-present) was characterized by a significant growth of their number in the Netherlands, as well as further broadening of their activities' focus. For example, according to the authors, $35 \%$ of the GIs engaged in collective production of heat or electricity and $50 \%$ of initiatives supplies green energy to consumers (usually via an intermediate supplier) [22].

While the contribution of Oteman, Kooij and Wiering adopts a historical perspective upon the development of local energy in the Netherlands, the work of Warbroek and Hoppe relies on the governance analysis of the initiatives in the Dutch provinces of Friesland and Overijssel. Whereas the perspective of Oteman, Kooij and Wiering presents the long term, nation-wide development and institutional fit of the GIs movement, Warbroek and Hoppe focus more specifically on contemporary regulatory response by local and provincial governments over the 2009-2016 period. The authors discuss local low-carbon energy initiatives (LLCEIs), which they define as 'the bottom-up initiating and managing of a project or series of projects involving the generation, stimulation and facilitation of low-carbon energy and energy efficiency by actors from civil society on a local scale' [23]. As compared to the contribution by Oteman, Kooij and Wiering, the authors emphasize a range of motivations behind 
LLCEIs, including 'environmental (e.g., carbon reduction, energy saving); economic (lower energy bill, local economic regeneration, job creation); and social drivers (community cohesion, social and civic gratification)' [23].

The discussion is taken further by Lammers and Diestelmeier, who focus on the energy initiatives' collective decentralized production [24] and by Saintier, who investigates the rise of Community Interest Companies, defined as 'consumers and local actors' collectives,' in the United Kingdom [25]. Saintier points out that the motivation of the UK government to support such initiatives 'is the non-commercial nature of such local actors and the hope that their involvement will combat NIMBYism' [25]. The author also makes an important observation regarding the discrepancy between the terminology used in various academic literature sources while referring to local energy initiatives [25]. This observation holds also for the contributions to the current special issue.

\section{Regulatory Approaches to Innovation in the Energy Market}

\subsection{The Role of Regulation in Addressing Innovation}

Compared to the discussion on the concept of innovation presented in the previous section, this section starts with a general overview of the role of regulation in relation to innovation. In this guest editorial and for the purposes of this special issue, regulation is defined in its broadest sense, as 'the sustained and focused attempt to alter the behaviour of others according to standards and goals with the intention of producing a broadly identified outcome or set of outcomes' [26]. This broad definition of regulation includes hard and soft law, as well as governance and does not limit itself to state-intervention.

Innovation is not a monolithic phenomenon. An invention occurs as either the result of deliberate and pointed research and development, or (more often) as the result of a 'happy accident' or serendipity [27]. A minor part makes it to the market, while the majority remains in the realm of inventions. The role of regulation in relation to invention is different from its role in relation to innovation. In relation to invention, the task of regulation is to ensure an environment conducive to inventions (e.g., competition, intellectual protection rights), as well as to 'filter out' the inventions that are socially undesirable, be it from economic, moral or ethical perspective (e.g., human cloning) [28]. In relation to innovation, the role of regulation could be described as minimizing the risks and maximizing the benefits [29]. Of course this role is continuous, rather than a one-off action.

The question is, then, how can regulation effectively fulfil its role in relation to innovation currently taking shape in the European energy market? Addressing this main question has been the ambitious goal of the current special issue. The two prospective answers that emerge across the contributions to this special issue, be it explicitly or implicitly, are regulatory alignment and regulatory innovation. Both are discussed in more detail in the next sections.

\subsection{Regulatory Alignment}

In relation to the regulatory approaches to innovation, alignment could have several meanings, namely: normative alignment, institutional alignment, instrumental alignment, organizational alignment and cultural alignment.

\subsubsection{Normative Alignment}

Normative alignment is related to consistency and coherence across institutional levels. The contribution by Scholten and Künneke [21] relies on Williamson's model of institutional levels [30]. More specifically, Williamson distinguished between informal institutions, formal institutions, 'play of the game' (modes of organization) and market activities [21]. Informal institutions comprise 'traditions, customs, norms and values' and they 'emerge spontaneously out of the interactions of millions of actors' [21]. Formal institutions refer to the 'rules of the game,' such as laws and regulations. The third level of 'play of the game' comprises 'the contractual arrangements among actors, i.e., the modes 
of organization that accommodate market transactions' [21]. Finally, the fourth level of institutions refers to 'short term market activities, company internal decision making on prices, quantities and investments, business models and optimization of operation and maintenance' [21]. According to the contributors to this special issue, normative alignment between the different levels of institutions is important for effectively addressing innovation.

\subsubsection{Institutional Alignment}

The concept of institutional alignment refers to the congruence between innovation on the one hand and the institutional setting on the other hand [22]. Of course, institutional alignment is closely related to normative alignment. The latter is vertical, as it refers to the coherence among different governance levels. The former is horizontal, as it implies a fit between institutions (at any level) and the innovation.

It is interesting to note that the contributors to this special issue define institutional alignment differently. Scholten and Künneke, for example, adopt a broad perspective upon it and focus upon socio-technical systems alignment. According to these authors, energy market and energy infrastructures are 'complex adaptive socio-technical systems whose performance $[\ldots]$ rests on the continuous interaction between its techno-operational characteristics, energy market dynamics and institutional arrangements' [21]. More specifically, the authors emphasize the need to align the technical infrastructure design with the market design and with the respective institutions and propose an initial framework of achieving a 'comprehensive design of energy infrastructures' [21].

Moreover, Scholten and Künneke raise an important fundamental question, namely: how much alignment should there be exactly? They conclude that 'perfect alignment is generally not perceived to be desirable,' as 'a certain degree of disalignment could be important to stimulate technical innovation and/or institutional reform' [21].

In contrast, the contribution of Oteman, Kooij and Wiering discusses institutional alignment in a narrower sense and focuses upon the 'institutional fit' between GIs on the one hand (as an example of innovation) and institutions on the other hand [22]. The authors adopt the definition of the institutions as 'the formal or informal procedures, routines, norms and conventions embedded in the organizational structure of the polity or political economy' [31]. They argue that the GIs in the Netherlands find an institutional fit at the regional (provincial) and at the local levels but lack such fit at the national level [22]. Moreover, Oteman, Kooij and Wiering conclude that the relationship between innovation and regulation 'can be characterized as GIs following policy changes, instead of GIs provoking regime changes' [22].

The narrow interpretation of institutional alignment is also adopted by Hufen in his contribution [19]. The author criticizes the Guarantees of Origin (GOs) system as it is currently introduced on the EU level and implemented in the Netherlands, from two main perspectives. His first critique is that the GOs do not, in fact, lead to an increase in overall European energy production and do not 'give impetus to an energy transition in the electricity market' [19]. This is due to the discrepancy in price for green electricity and consequently for GOs, among European countries. For example, Nordic countries, such as Iceland, Norway, Sweden and Finland, produce a large portion of their domestic electricity demand from hydro-a renewable energy source. Consequently, almost all electricity the Nordic electricity consumers receive is green electricity and they are not interested in it being certified as such and having a GO. For example, less than $1 \%$ of total possible GOs are redeemed in Iceland [19]. The rest of the GOs could be exported to the other EU member states, where suppliers will use them to administratively green the so-called grey (fossil-based) electricity delivered to consumers. However, the revenues from GOs are too low to stimulate additional investments in the renewable energy production in the exporting countries. Indeed, Hufen notes that it is possible to administratively sell to consumers a 100\% renewable energy and to physically sell them $100 \%$ coal energy [19]. This leads to the second critique of GOs system presented by this author and namely that greening grey electricity by the means of GOs is misleading the consumers. 
He argues that most consumers are 'not aware of the true nature of products and are therefore not able to choose the product that fits their needs' [19].

\subsubsection{Instrument Alignment}

Instrument (al) alignment could be defined as the appropriateness of the regulatory instrument for the task at hand. The contributions by Warbroek and Hoppe [23] and by Grotenbreg and Van Buuren [32] to the current special issue are particularly interesting in the context of such alignment, as both discuss the concept of meta-governance. Meta-governance is defined as the strategic activities of government in relation to governance' [23]. From this perspective, the government is seen as a meta-governor that 'mobilizes the relevant actors, public and private, governmental and non-governmental, around a certain public problem and structures their interaction' [32]. Warbroek and Hoppe differentiate between two modes of meta-governance: (i) by enabling and (ii) by authority [23]. The former 'entails coordinative and facilitative activities,' while the latter 'involves directive and regulative activities' [23]. Thus, in addition to the traditional command and control regulatory instruments, the government could choose to use 'institutional design, coordination, subsidy schemes, network and process management, or framing and storytelling to achieve its policy goals' [32].

Enabling governance involves the transfer of authority and decision-making to actors other than the government itself. It entails less governmental involvement (also in terms of resources), however it also offers less certainty that the envisaged results will be achieved. Both contributions by Warbroek and Hoppe [23] and by Grotenbreg and Van Buuren [32] reach similar findings and namely that selecting an appropriate governance instrument is important for reaching the envisaged results. In other words, the task at hand and the circumstances associated with it should be considered when the choice is made in favour of either enabling or authoritative governance. Indeed, Grotenbreg and Van Buuren note that no matter how enticing the enabling governance arrangement is, it 'will not automatically lead to private action' [32]. It will only be successful if external 'actors can bring resources into the governance process that the government lacks, such as knowledge or money, especially in times of austerity' and if these actors are, in fact, interested to take up this additional responsibility [32]. If this is not the case, in order to achieve results, 'the government's facilitative role [ ... ] needs to go hand in hand with more 'traditional' government roles, such as those of provider, contractor and/or financier' [32].

This authority transfer from the government to private actors is also discussed by Saintier, who focuses upon the emergence of prosumers in the UK energy market [25]. Prosumers are energy consumers who also engage in the energy production to satisfy (a part of) their demand. With the emergence of prosumers, the spread between the consumer groups increased, with vulnerable consumers on one end of the spectrum and prosumers on the other. Saintier notes that the current regulatory and governance models of the energy sector leave vulnerable consumers unprotected and fail to empower prosumers' [25]. In other words, her findings are illustrative of the lack of alignment between the innovations that enabled such spread between consumer groups in the market and the respective regulatory instruments.

\subsubsection{Organizational Alignment}

Organizational alignment can also be defined as internal alignment, because it refers to the alignment of the internal structure of an organization with its goals and tasks. Two contributions stand out in relation to this type of alignment-that by Saintier [25] and that by Oteman, Kooij and Wiering [22]. Saintier points out that 'in order for a local energy actor to succeed, it is important [ ... ] to have a clear idea as to what they want to do but also to have realistic expectations as to what can be done within the community they are in, geographically as well as representing the people of the community' [25]. In their contribution, Oteman, Kooij and Wiering similarly show that the motivations behind the GIs largely determine their activities, business models and organizational structure [22]. 


\subsubsection{Cultural Alignment}

Finally, cultural alignment between the norms and values associated with a specific innovation and the institutional setting is of importance. One contribution to the current special issue stands out in relation to cultural alignment-that by De Jong, Stout and Sun [33]. Countries outside the EU try to learn from regulatory responses to energy innovations in EU countries. A major importer of these valuable 'lessons' is China. China and the EU developed a partnership on climate change in 2005 (renewed in 2015), from which a host of collaborative agreements were signed between Chinese and various European partners [33]. This was extended to another high-level partnership on sustainable urbanization, leading to a wave of Sino-European cross-national and cross-city agreements. In their article, De Jong, Stout and Sun address how the Chinese central government has undertaken a variety of measures, including the launch of large Sino-European programs, to learn from 'developed nations,' often coining 'sustainable urbanization' as a synonym to cope with key societal and environmental challenges like low carbon energy transition [33]. The authors observe a mismatch in normative conceptions Chinese and European participants have about governance of these challenges. A particularly related normative issue concerns how 'good governance' plays a role in these endeavours. Insights are taken from Montesquieu's 'The Spirit of Laws' regarding 'checks and balances' and 'trias politica' (which the authors update to 'sextas politica' for the 21st century) to comprehend how the exertion of power is distributed [33]. In the authors' view, 'good governance' and 'sextas politicas' are not only relevant to design and exertion of governance of (urban and regional) low carbon energy in China but should however also be adhered to in a European setting (assuming that Montesquieu's concepts do not automatically apply to all Western countries) [33].

\subsection{Regulatory Responses to Innovation}

\subsubsection{Different Ways to Respond to Energy Innovations}

When looking into the set of regulatory responses to innovation in the EU energy sector, presented in the articles contributing to this special issue, different sorts are identified. Whereas some focus on typical top down (assumingly harmonized) implementation of policy from the EU to the national level (i.e., the GO system reported in Hufen [19]), other focus more on the regulatory responses to technical and social innovations that emerge in a bottom-up fashion. The latter address energy communities, GIs for renewable energy, community energy services, shareholder projects and the like (Oteman, Kooij \& Wiering [22], Warbroek \& Hoppe [23], Saintier [25], Heldeweg [34]). In these approaches, governance not only concerns (modes of) public governance but also conveys (modes of) societal self-governance. Arguably, the latter adds more complexity to the already complex governance arrangements found in the liberalized energy sector of the European Union. A third type of regulatory response addressed in the contributions concerns experimentation. It addresses current flaws in experimentation legislation and addresses the institutional and legal conditions under which experiments with energy innovations can prosper and evoke adaptation of regulatory frameworks (Lammers \& Diestelmeier [24], Heldeweg [34], Warbroek \& Hoppe [23]).

\subsubsection{New Policy Instruments?}

When zooming in into the governance approaches and policy instruments discussed in the articles it makes sense to use a categorization. To do so we will use the traditional "sermon, carrot, stick" classification [35]. Traditional policy instruments used in the energy domain are mainly regulation and economic incentives. Mentioning of economic incentives/policy instruments ('carrots') are found in most of the contributions, e.g., subsidies, tax incentives, feed-in-tariff, capacity building schemes and more innovative economic instruments like the so-called 'Zipcode rose' to spur collective decentralized renewable energy production by (members of) local sustainable energy cooperatives and share-ownership projects (Hufen [19], Scholten \& Künneke [21], Warbroek \& Hoppe [23], Saintier [25], Oteman, Kooij \& Wiering [22]). 
Regulation (the 'stick') is addressed in many of the contributions to this special issue. Hufen [19] addresses a market-based certification system that goes along with the top-down implementation of EU renewable energy directives. Warbroek \& Hoppe [23] address the rather authoritative ways in which government engages with GIs for renewable energy. Sectoral regulations have a vast impact on decentralized governance, causing many civil servants to act as 'wounded lions,' clinging to strict interpretation and hence implementation of permit systems and other regulatory necessities, causing institutional inertia and a lack of adaptive capacity to cope with emerging social innovations in the energy sector. Lammers \& Diestelmeier [24], Warbroek \& Hoppe [23] and Heldeweg [34] address legal practices and instruments under which experiments with renewable energy innovations take place. They observe vast restrictions that impede good use of the experiments regarding institutional learning and adaptation and call for reflexive meta-governance and creation of designing absorptive and resistant institutional settings, while meanwhile allowing for self-regulation within instantiations of legal institutions, to organize (governance) experiments.

Communicative instruments (the 'sermon') have been addressed in multiple contributions to this special issue. A good example of one of the more innovative instruments in this regard, concerns ways in which government facilitates private sector projects via 'discursive framing' as a way to 'govern' complex multi-actor projects (Grotenbreg \& Van Buuren [32]). Government initiates projects and invites private parties to partake and contribute. However, the use of the instrument should not be overrated, as there is only so much governments can do with it. If there is not sufficient operational capacity with the private parties and there is not sufficient use of other (economic or legal) instruments, the likelihood of having impact is low. Another way communicative instruments are used is in (large-scale) projects targeted at learning and capacity building; e.g., to support GIs in setting up projects, or offering them knowledge via platforms and workshops (Warbroek \& Hoppe [23]).

\subsubsection{Multiple Levels of Governance}

A key conflicting force the European energy market is experiencing, is a multi-level governance issue. On the one hand, there is a push towards more centralization on the European level but on the other hand there is a pull towards more decentralization on the national level. The push towards more Europeanization and harmonization is exemplified by the study by Hufen [19] on the implementation of the GO system, which suffered a great deal from national politics and governments wanting to steer national implementation in certain ways following their own normative-economic governance orientations. In the Dutch case, central government clearly had other priorities. Aside from Hufen's contribution the other contributions to the special issue provided more information regarding a pull towards more decentralization on the national level.

The articles on GIs for renewable energy (Oteman, Kooij \& Wiering [22], Warbroek and Hoppe [23], Saintier [25], Heldeweg [34]) revealed an image on emerging regulatory responses by decentral governments, in the absence of national government's regulatory response. Although most EU member states have feed-in-systems in place nowadays, national governments did not do much substantially in response to emergence of the GIs besides launching episodic instruments like the so-called 'Zipcode rose' (implemented in the Netherlands) and allowing for some degree of experimentation. In a country like the Netherlands, these regulatory responses should be seen in the periphery of national energy policy, which prefers policies adhering to the core values of security of supply, economic efficiency, market liberalization and showing little attention to supporting GIs. When it comes to experimentation, however, the national government, in the case of the Netherlands, did show a proactive regulatory response. It succeeded in creating the conditions under which experiments with decentralized energy supply (even involving a vast number of GIs) could be undertaken, i.e., by formal 'policy experiments,' 'Green Deals,' the 'IPIN' program and the Experimentation Decree as reported by Lammers \& Diestelmeier [24]. Despite their restrictions, these experiments gave room to stakeholders to learn about niche and business case development of decentralized energy innovation and related legal and governance challenges. For instance, raising attention to 'prosumption' and calling for 
codification of 'prosumers' in (EU) energy law [36]. Moreover, it is in these experimental settings that multiple levels of government collaborate in fruitful ways to spur innovation. In addition, one should not forget that the European Union is also heavily involved in supporting experimentation with energy innovations via its research and structural programs, like FP7, FP8 and Horizon 2020.

In summary, we conclude that regulatory response to innovation in the European energy market comes from all levels of government, some responding earlier and more intense than others do. And whereas certain programs and instruments can be viewed as strict forms of vertical top-down Europeanization, there is a plethora of regulatory responses by local and regional governments that reflect bottom-up and even horizontal forms of Europeanization [3]. Given the co-existence of the two (or even three models of Europeanization) there are 'grey areas' in which Europeanization models overlap. Anyway, empirical evidence in the current special issue reveals that innovation in the European energy market requires both top-down and bottom-up responses. Regarding the latter, it is perhaps fair to state that next to adhering to the traditional levels of public multilevel governance, a localized level of societal self-governance can be added.

\subsubsection{Multi-Actor Complexity}

Aside from multi-level governance the European energy market is experiencing the conflicting force of a multi-actor governance issue, such as the governance of decentralized RES production by citizens, as well as market and government actors. The contributions to this special issue show different ways in which multi-actor complexity manifested in the European energy sector.

First, prosumers and GIs have emerged as stakeholders in energy systems and come with novel community energy services, cooperative organisations, share-owner and related (investment) projects. Regulatory responses have led to even more multi-actor complexity as different organisational capacity building platforms and representative (umbrella) organisations have emerged, forming organisational entities of themselves. The emergence of these new actors also comes with new forms of (self-)governance and forms of enabling and networked forms of governance, while creating pressure on traditional modes of governance by authority. The question also emerges how to 'merge' or 'synergize' modes of self-governance with the more traditional forms of governance in the energy sector (see the articles by Oteman, Kooij \& Wiering [22], Warbroek \& Hoppe [23], Heldeweg [34], Saintier [25]). Second, multi-actor complexity was shown by the influential role NGOs and energy consumers representative organisations had on the implementation process of the GO system (Hufen [19]). This demonstrated the importance of the involvement of actors that often reside outside or on the boundaries of energy regimes. Third, the current special issue provides insights on strategies and policies on how to cope with the emerging and increasing degree of complexity in the energy sector and in particular in decentralized renewable energy projects. An approach getting special attention in this regard, concerns facilitating by discursive framing, as introduced in the contribution by Grotenbreg \& Van Buuren [32]. Fourth, learning to cope with multi-actor complexity in protected spaces-organizing experiments that allow for learning about organisational, technical and economic performance and emerging governance of promising energy technologies-is important to make regulatory frameworks adaptive to reshape and embed those innovations. Having legal frameworks in place that restrict these forms of experiments could be seen as a governance challenge. Fifth, it is important to pay sufficient attention to multi-actor complexity in the design of energy infrastructure and formulation of related policy (Scholten \& Künneke [21]). While doing this it is important to make sure that (multi-actor) decision-making central to these processes is properly designed and managed [37]. Finally, it is important to address democratic values in multi-actor governance of energy innovations. This should entail separation of powers, include control mechanisms and therefore could imply to use the 'sextas politica' concept introduced by De Jong, Stout \& Sun [33] to reflect on ongoing governance practices in the energy sector and on the design of new forms of governance in response to the emergence of energy innovations. 


\section{Observations and Conclusions}

\subsection{Disciplinary Contributions}

The contributions to this special issue offer a broad array of disciplinary approaches, all relevant to the analysis and design of governance of energy systems and markets. First, there are empirical contributions focusing on experiences with 'institutional (mis)fit,' implementation of certain policy instruments and programs and new modes of (self) governance. Most of these contributions adhere to disciplines of public administration and public policy (Hufen [19], Warbroek \& Hoppe [23], Oteman, Kooij \& Wiering [22], Grotenbreg \& Van Buuren [32]). However, there are also reflective normative-legal studies that address the role of regulatory frameworks in relation to emerging phenomena such as GIs for renewable energy and the extent to which public values like energy justice are addressed (i.e., Saintier [25], Heldeweg [34]). In a similar legal reflective manner attention is paid to experiences with experimentation of decentralised renewable energy systems and the emerging governance challenges they evoke (Lammers \& Diestelmeier [24], Heldeweg [34]). Besides these two disciplinary approaches (illustrating the 'law and policy' perspective that is central to this special issue), additional conceptual-normative and prescriptive contributions are made. Scholten \& Künneke [21] introduce a comprehensive design framework that can be used to analyse and design institutional-economic and governance arrangements and related regulatory frameworks in the light of emerging energy technologies. Heldeweg [34] introduces conceptual insights that can be used to analyse and design forms of legal governance in response to emerging innovations in the energy sector. Finally, De Jong et al. (2017) introduce a concept entitled 'sextas policitica' (based and expanded from Montesquieu's 'trias politica'), which can be used to reflect on current regulatory frameworks and energy sectors, to judge whether there are sufficient 'checks and balances' (i.e., control systems) to safeguard a sound, effective and at the same time democratic, legitimate functioning of these systems. As such, it can be seen as a 'good governance' heuristic that can be used to critically reflect on the division of societal and governmental powers in energy systems.

\subsection{Conclusions and Recommendations for Further Research}

This special issue set out with the research question whether the existing regulatory framework sufficiently allows for innovation in the European energy sector and supports its further development. The nine article contributions to this special issue have shown that current regulatory frameworks only to a certain, reasonable extent, can be judged as being capable to allow for such innovation.

When looking to academic contributions these articles introduced a broad set of conceptual and empirical contributions to the emerging field of energy governance, while taking both a law and policy perspective. They entailed: insights on different regulatory responses to innovation in energy sectors, new conceptual and analytical approaches to innovations (in particular regarding GIs) in the energy sector, innovative (legal, institutional and governance) design frameworks and novel perspectives on multi-level governance, multi-actor complexity and policy instruments.

We finalize this guest editorial note with recommendations for future research that we summarized from the article contributions.

A common EU response to energy innovation concerns the traditional way of issuing directives and implementing them in a harmonized 'top down' fashion in EU Member States. In his contribution to this special issue Hufen [19] showed that the introduction of a market-based system (the system on Guarantees of Origin of renewable energy supply), along with government-led economic incentives did support increasing the uptake of renewable energy in domestic energy consumption in a Member State (i.e., the Netherlands) but that the system was subjected to heavy criticism. Consumer representatives and NGOs openly criticized the system for "cheating green electricity". The study revealed the important role of consumer organizations, NGOs and public opinion in the implementation process, as well as the flaws and national politics interests that impede sound harmonized implementation across EU Member States. In following this study, from an editorial viewpoint, we would like to recommend an international study of the market-based system in all participating countries. 
The Dutch experiences are an interesting but small part of the puzzle. Furthermore, the critical and very constructive role of consumer representatives in decision-making processes deserves further attention.

As discussed in the above, particularly in Section 3.3.2, the article contributions display a plethora of (new) policy instruments and (new) regulatory responses. Surely these cannot adequately be understood merely in terms of a 'top-down' (state) versus 'bottom-up' (market) dichotomy. Further, even the traditional "sermon, carrot, stick" classification, that was used in the above to discuss some new policy instruments, does not provide the analytical tool to determine if the innovation of the European energy sector leads to what may be labelled 'regulatory innovation'. Following Julia Black [26], such innovation would be at play in case of so-called 'third order regulatory changes', or regulatory 'paradigm shifts', which are "changes in the cognitive or normative framework of the regulatory regime". As such regulatory innovation would move beyond 'second order changes' of changes in regulatory techniques or processes, such as of the above classification of policy instruments or the fourfold regulatory strategies as distinguished by Murray and Scott [38], of hierarchy-based, competition-based, community-based and design-based regulatory approaches. Regulatory innovation would more likely correlate with the types of shifts in governance that came across in some of the contributions, such as of Scholten \& Künneke [21] and of Heldeweg [34] and more broadly would relate to the concept of 'meta-governance' as applied in the contributions by Warbroek and Hoppe [23] and by Grotenbreg and Van Buuren [32]. From an editorial viewpoint, we suggest that further conceptual research is done towards a taxonomy that not only encompasses policy studies and regulatory theory typologies but which may also provide a tool to identify and analyse regulatory innovation, also in respect of effectiveness and legitimacy of such innovations related to meta-governance.

We argue that it is important to pay more attention to research into experimental and design processes that have to do with the institutional and legal perspectives of energy governance modes, thereby adhering to the frameworks presented by Scholten \& Künneke [21] and Heldeweg [34]. Although the comprehensive design framework by the former looks promising regarding analytical use by academic researchers and design oriented work by policy makers, as to date the framework remains untested, while insufficiently operationalized nor scrutinized. Moreover, improvements can be made regarding the operationalization of the desired degree of alignment between the system and market design, its static nature, the role of agency in the framework, the conceptual incorporation of ICT and further operationalization of what exactly changes in one dimension imply for other dimensions. Most urgent is the need to further develop the concept of alignment between the design variables of both dimensions along the three layers, i.e., along the notions of access, responsibility and coordination, in order to have the ability to identify inconsistencies between market and system designs.

Regarding the framework on legal governance design and normative resilience (Heldeweg [34]) it is suggested that further study is necessary to understand relations between modes of governance both at the constitutional and collective choice levels, also with respect to the design of institutional hybridity and parallelism and of normative resilience. Legal design needs to reconcile or choose between the duelling frames of 'democratization' and 'expansion' and avoid a vagueness of normative integrity that would ultimately pose a threat to properly and resiliently balancing public service dimensions. Heldeweg [34] also calls for more research into the relationship between the energy trilemma and energy justice from a legal governance perspective. To determine the full potential of community energy services requires that further research is conducted that links empirical and legal governance studies concerning the design and functioning of institutional environments (as legal institutions), especially as regards the legal space of 'civil energy networks,' their requirements to normative alignment and their normative resilience.

As regards research about governance and facilitation of community energy, in line with Warbroek \& Hoppe [23] from an editorial viewpoint we suggest that future research is needed with respect to the effectiveness of different policy instruments and practices that governments implement to support GIs for renewable energy. This especially concerns unintended and side effects of economic incentives like subsidies. In addition, research is required to explore the effects of such practices on existing 
institutional and policy arrangements for GIs. Furthermore, we suggest that more research is needed with regard to institutional inertia and misfit vis-à-vis social energy innovations like GIs (in line with Oteman, Kooij \& Wiering [22]). We also suggest that medium to large-N quantitative research is needed among subnational governments in order to determine the factors influencing the extent and shape of innovations in governing vis-à-vis the emergence of community energy.

Another issue that was frequently addressed in our special issue, concerned (the conditions to spur sound) experimentation with energy innovations and applicable governance modes (Lammers \& Diestelmeier [24], Heldeweg [34], Warbroek \& Hoppe [23]). The article by Lammers \& Diestelmeier [24] showed that in practice, experiments and the legal framework under which they serve, are very restrictive, which limits their contribution to the design and adaptiveness of regulatory frameworks to energy innovations. In following the authors, the editorial board suggests that on the one hand, further research is needed into new, not-too-restricted modes of governance for decentralized energy systems, whereas on the other hand, it is paramount to investigate the coordination of national and EU-level developments to prevent undesired, non-legitimate and unequal developments.

We also want to stress some limitations of this special issue. The articles in it only embody studies that are either conceptual in nature and/or used qualitative (empirical) research methods. Next to continuing research along these lines the editorial board suggests that it would also be desirable to explore avenues of research using quantitative research designs. It is also suggested that in future research studies are undertaken in European countries outside the Netherlands and the United Kingdom (referring to the fact that seven out of nine of the articles presented in the current special issue entail case studies of and within these countries, especially the Netherlands).

Acknowledgments: The authors would like to express their gratitude to the authors who contributed to this special issue and the Netherlands Institute of Government studies (NIG), which financed its publication.

Author Contributions: Thomas Hoppe, Anna Butenko and Michiel Heldeweg co-edited the special issue and wrote this guest editorial note together.

Conflicts of Interest: The authors declare no conflict of interest. The founding sponsors had no role in the design of the study; in the collection, analyses, or interpretation of data; in the writing of the manuscript and in the decision to publish the results.

\section{References}

1. Negro, S.O.; Alkemade, F.; Hekkert, M.P. Why does renewable energy diffuse so slowly? A review of innovation system problems. Renew. Sustain. Energy Rev. 2012, 16, 3836-3846. [CrossRef]

2. Arentsen, M.J.; Künneke, R.W. Economic organization and liberalization of the electricity industry: In search of conceptualization. Energy Policy 1996, 24, 541-552. [CrossRef]

3. Jörgens, H.; Solorio, I. (Eds.) A Guide to EU Renewable Energy Policy; Edward Elgar: Cheltenham, UK, 2017.

4. Hoppe, T.; van Bueren, E.; Sanders, M. Naar een bestuurswetenschappelijke onderzoeksagenda voor klimaatmitigatie in Nederland en Vlaanderen. Bestuurswetenschappen 2013, 67, 88-99.

5. Hoppe, T.; van Bueren, E. Guest editorial: Governing the Challenges of Climate Change and Energy Transition in Cities. Energy Sustain. Soc. 2015, 5, 1-9. [CrossRef]

6. Hoppe, T.; van Bueren, E.; Sanders, M. Besluit themanummer 'Energietransitie en lokaal bestuur'. Bestuurswetenschappen 2016, 70, 75-79. [CrossRef]

7. Greenhalgh, C.; Rogers, M. Innovation, Intellectual Property, and Economic Growth; Princeton University Press: Princeton, NJ, USA, 2010.

8. Ranchordás, S. Constitutional Sunsets and Experimental Legislation: A Comparative Perspective; Edward Elgar: Cheltenham, UK, 2014.

9. Jordan, A.; Huitema, D. Policy innovation in a changing climate: Sources, patterns and effects. Glob. Environ. Chang. 2014, 29, 387-394. [CrossRef]

10. Dewar, R.D.; Dutton, J.E. The Adoption of Radical and Incremental Innovations: An Empirical Analysis. Manag. Sci. 1986, 32, 1422-1433. [CrossRef]

11. Christensen, C. The Innovator's Dilemma: When New Technologies Cause Great Firms to Fail; Harvard Business School Press: Boston, MA, USA, 1997. 
12. Gans, J. The Disruption Dilemma; The MIT Press: Cambridge, MA, USA, 2016.

13. Joshua Gans' Website. Available online: https://www.joshuagans.com/the-disruption-dilemma/ (accessed on 5 December 2017).

14. Henderson, R.M.; Clark, K.B. Architectural Innovation: The Reconfiguration of Existing Product Technologies and The Failure of Established Firms. Admin. Sci. Q. 1990, 35, 9-30. [CrossRef]

15. Chesbrough, H.W. Open Innovation: The New Imperative for Creating and Profiting from Technology; Harvard Business School Press: Boston, MA, USA, 2006.

16. Chesbrough, H.W. Everything You Need to Know About Open Innovation. Available online: https://www.forbes.com/ sites/henrychesbrough/2011/03/21/everything-you-need-to-know-about-open-innovation/\#79b2c71775f4 (accessed on 5 December 2017).

17. Von Hippel, E. Democratizing Innovation; The MIT Press: Cambridge, MA, USA, 2005.

18. Aghion, P.; Howitt, P. The Economics of Growth; The MIT Press: Cambridge, MA, USA, 2009.

19. Hufen, J.A.M. Cheat Electricity? The Political Economy of Green Electricity Delivery on the Dutch Market for Households and Small Business. Sustainability 2016, 9, 16. [CrossRef]

20. The European Parliament and the Council of the European Union. Article 2.j, Directive 2009/28/EC of the European Parliament and of the Council of 23 April 2009 on the Promotion of the Use of Energy from Renewable Sources and Amending and Subsequently Repealing Directives 2001/77/EC and 2003/30/EC. Off. J. Eur. Union 2009, 5, 6.

21. Scholten, D.; Künneke, R. Towards the comprehensive design of energy infrastructures. Sustainability 2016, 8, 1291. [CrossRef]

22. Oteman, M.; Kooij, H.J.; Wiering, M.A. Pioneering renewable energy in an economic energy policy system: The history and development of Dutch grassroots initiatives. Sustainability 2017, 9, 550. [CrossRef]

23. Warbroek, B.; Hoppe, T. Modes of governing and policy of local and regional governments supporting local low-carbon energy initiatives; exploring the cases of the Dutch regions of Overijssel and Fryslân. Sustainability 2017, 9, 75. [CrossRef]

24. Lammers, I.; Diestelmeier, L. Experimenting with Law and Governance for Decentralized Electricity Systems: Adjusting Regulation to Reality? Sustainability 2017, 9, 212. [CrossRef]

25. Saintier, S. Community Energy Companies in the UK: A Potential Model for Sustainable Development in "Local" Energy? Sustainability 2017, 9, 1325. [CrossRef]

26. Black, J. What is Regulatory Innovation? In Regulatory Innovation; Black, J., Lodge, M., Thatcher, M., Eds.; Edward Elgar: Cheltenham, UK, 2005.

27. Meyers, M.A. Happy Accidents: Serendipity in Modern Medical Breakthroughs; Arcade Publishing: New York, NY, USA, 2007.

28. Butenko, A.; Larouche, P. Regulation for innovativeness or regulation of innovation? Law Innov. Technol. 2015, 7, 52-82. [CrossRef]

29. Bennett Moses, L. How to Think about Law, Regulation and Technology: Problems with "Technology" as a Regulatory Target. Law Innov. Technol. 2013, 5, 1-20. [CrossRef]

30. Williamson, O. Transaction cost economics: The governance of contractual relations. J. Law Econ. 1979, 22, 233-261. [CrossRef]

31. Wiering, M.; Arts, B. Discursive shifts in Dutch river management: 'Deep' institutional change or adaptation strategy? In Living Rivers: Trends and Challenges in Science and Management; Leuven, R.S., Ragas, A.M.J., Smits, A.J.M., van der Velde, G., Eds.; Springer: Dordrecht, The Netherlands, 2006; pp. 327-338.

32. Grotenbreg, S.; van Buuren, A. Facilitation as a Governance Strategy: Unravelling Governments' Facilitation Frames. Sustainability 2017, 9, 160. [CrossRef]

33. De Jong, M.; Stout, H.; Sun, L. Seeing the People's Republic of China through the Eyes of Montesquieu: Why Sino-European Collaboration on Eco City Development Suffers from European Misinterpretations of "Good Governance". Sustainability 2017, 9, 151. [CrossRef]

34. Heldeweg, M.A. Normative Alignment, Institutional Resilience and Shifts in Legal Governance of the Energy Transition. Sustainability 2017, 9, 1273. [CrossRef]

35. Bemelmans-Videc, M.L.; Rist, R.C.; Vedung, E.O. (Eds.) Carrots, Sticks, and Sermons: Policy Instruments and Their Evaluation; Transaction Publishers: Piscataway, NJ, USA, 1998.

36. Lavrijssen, S.; Carrillo Parra, A. Radical Prosumer Innovations in the Electricity Sector and the Impact on Prosumer Regulation. Sustainability 2017, 9, 1207. [CrossRef] 
37. De Bruijn, H.; Ten Heuvelhof, E.; In 't Veld, R. Process Management. Why Project Management Fails in Complex Decision Making Processes; Springer: Dordrecht, The Netherlands, 2010.

38. Murray, A.; Scott, C. Controlling the new media: Hybrid responses to new forms of power. Mod. Law Rev. 2002, 65, 491-516. [CrossRef]

(C) 2018 by the authors. Licensee MDPI, Basel, Switzerland. This article is an open access article distributed under the terms and conditions of the Creative Commons Attribution (CC BY) license (http:/ / creativecommons.org/licenses/by/4.0/). 